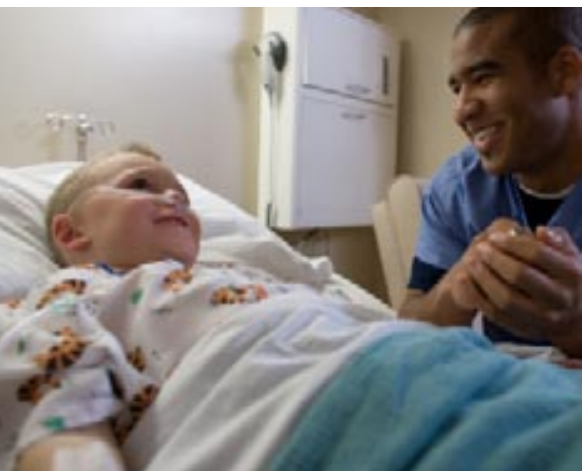

\section{ROLE OF THE DOCTOR}

\section{To care for patients' wellbeing}

It may help us to understand our core role as doctors if we understand and accept the responsibilities that come from being a member of a "profession." and concept I relate to was expressed by John K Davies back in 1991. ${ }^{2}$

He thinks a professional's duty is not primarily to please but to do or advise the "right" thing. Usually, this pleases as well as alleviating the problem, but what is said or advised may not be what the patient wants to hear. The integrity of the doctor and what gives him or her professional status is the willingness and ability to take a difficult or unpopular stance because he or she knows, in good faith and not paternalistically, that this is the best advice, informed by up to date knowledge and opinion.

Doctors are in a privileged position, and the concept of professionalism described above is perhaps subconsciously recognised by society in awarding that privilege. With that privilege comes a responsibility to always act professionally by being well informed and being able and prepared to provide "tough love" if necessary. In my opinion, we are prepared to do this because we care.

The irreducible core value of a doctor is that he or she cares for the wellbeing of his or her patients. Our purpose for practising medicine is in danger of being lost if we cannot undertake this role because of management and professional practices that emphasise process and productivity. If doctors cannot satisfactorily care for their patients then their reason to remain in the profession and maintain the required standards will be lost, leading to disillusionment and perhaps the loss of morale we see at present.

Richard D Colman occupational physician, York YO62 7JW richardcol@doctors.org.uk

Competing interests: None declared.

1 Godlee F. The role of the doctor. Editor's choice. BMJ 2007;335. (17 November.)

2 Davies JK. Professions, trades and the obligation to inform. J Appl Philosophy 1991;8:168.

\section{Behold the factory worker}

The foundation year 1 (F1) doctor's role is like that of a factory worker. ${ }^{1} \mathrm{He}$ or she must look at the patient simply as a product on the conveyor belt of the NHS factory. All empathic sentiments must be left with their coats when the workers clock in at 830 am. Any emotional feelings about the product (patient) or extra time spent talking to it would only waste valuable factory time. The product must get through the system in the specified time and the factory worker (F1 doctor) must commit all his or her energy to making sure that as many products get on to the conveyor belt as quickly as possible.

The new factory worker emerging from Modernising Medical Careers must be cold and unfeeling. He or she must also be reasonably efficient, although cutting corners is acceptable as long as the product has a label (diagnosis) on it. The supervisors (consultants and registrars) do not usually check that all the labels are correct as they are so busy themselves, usually in another part of the factory. So even the correct label is not important, the only thing that matters is that the labels are slapped on as quickly as possible and that the products look as if they are finished. Unfortunately, the products often break again after leaving the factory, but that doesn't matter as long as the managers can tick the boxes on their clip boards and count that the right number of products are delivered for the target count at the end of the day.

Jane A Calne honorary senior lecturer, UEA School of Medicine Health Policy and Practice, Norwich NR4 7TJ agacalne@ukonline.co.uk

Competing interests: None declared.

1 Godlee F. The role of the doctor. Editor's choice. BMJ 2007;335. (17 November.)

\section{GRADUATE MEDICAL SCHOOL ENTRY}

\section{Bad for poorer applicants}

I take issue with the assertion that candidates are somehow "stronger" for a previous degree and "life experience." Candidates from poorer backgrounds have been totally disadvantaged by the changes in maintenance grants and the introduction of tuition fees.

It is not economically viable for these kinds of entrants to have done a previous degree, as their medical degree would be unaffordable because of the levels of debt sustained during their first degree and the fact they must pay for at least a part of their medical degree.

Andrew D Beggs research registrar surgery, London andrewbeggs@gmail.com

Competing interests: None declared.

1 Peile E. Should all medical students be graduates first? Yes. BMJ 2007;335:1072. (24 November.)

\section{ATRIAL FIBRILLATION}

\section{Rate control and digoxin}

Nikolaidou and Channer's editorial suggests that no single definition of ideal control of heart rate in chronic atrial fibrillation (AF) exists, ${ }^{1}$ but current recommendations are between 60 and 90 beats/min at rest and between 90 and 180 beats/min during moderate exercise. ${ }^{2}$ However, no controlled clinical trials have validated these target rates for preventing all-cause cardiovascular morbidity or mortality, and the best method for assessing rate control is unclear. ${ }^{3}$ Adequate rate control may encompass more than preventing fast ventricular rates. ${ }^{2}$ The editorial also confuses rate control of $\mathrm{AF}$ per se and the use of digoxin for comorbidities such as heart failure. ${ }^{1}$ Their overview of AF rate control (with no critical appraisal of published studies) mixes studies of digoxin monotherapy and combination therapy of digoxin and $\beta$ blockers.

NICE has provided clear recommendations on rate control. ${ }^{2}{ }^{4} \mathrm{We}$ recommend $\beta$ blockers or rate limiting calcium antagonists as initial monotherapy in all patients. We do not exclude digoxin, although it is probably less good overall as monotherapy but useful in sedentary 
patients. If monotherapy fails, we recommend combined $\beta$ blockers or rate limiting calcium antagonists and digoxin to control heart rate during normal activities, and rate limiting calcium antagonists and digoxin during both normal activities and exercise.

A Clinical Evidence review on chronic AF came to similar conclusions ${ }^{2}$ and another recommends intravenous rate limiting calcium antagonists or $\beta$ blockers for urgent rate control. ${ }^{5}$

The NICE guidelines do not contraindicate digoxin, but the limited evidence suggests that $\beta$ blockers and rate limiting calcium antagonists are better for rate control per se. Digoxin may be useful for comorbidities (such as heart failure) but combination therapy is often used.

Gregory Y H Lip clinical adviser, Guideline development group for the NICE clinical guideline for the management of atrial fibrillation g.y.h.lip@bham.ac.uk

Michael Rudolf chair, Clinical Guideline Group, NICE,

London WC1V 6NA

Competing interests: GYHL is clinical adviser and MR is chair of the guideline development group for the NICE clinical guideline for the management of atrial fibrillation.

1 Nikolaidou T, Channer KS. Rate control in permanent atrial fibrillation. BMJ 2007;335:1057-8. (24 November.)

2 Camm AJ, Savelieva I, Lip GY; Guideline Development Group for the NICE clinical guideline for the management of atrial fibrillation. Rate control in the medical management of atrial fibrillation. Heart 2007;93:35-8.

3 Boos C, Lane D, Lip GYH. Atrial fibrillation (chronic). Clinical Evidence 2007 http://clinicalevidence.bmj. com/ceweb/conditions/cvd/0217/0217.jsp

4 National Collaboration Centre for Chronic Conditions. Atrial fibrillation: national clinical guideline for management in primary and secondary care. London Royal College of Physicians, 2006.

5 Lip GYH, Watson T. Atrial fibrillation (recent onset). Clinical Evidence 2007 http://clinicalevidence.bmj. com/ceweb/conditions/cvd/0210/0210.jsp.

\section{INVESTIGATING RENAL IMPAIRMENT}

\section{Angioplasty's role is uncertain}

Ratnam et al take a one sided radiological view of investigating progressive unexplained renal impairment and hypertension. ${ }^{1}$ Many small studies have investigated whether renal artery angioplasty is better than medical intervention, and none is conclusive either way. The risks from angioplasty have not been mentioned (renal artery occlusion and silent loss of the kidney). An ongoing randomised trial (Astral) will hopefully answer this question.

The authors also comment on a "high level of cholesterol," but this does not equate to the British Hypertension Society guidelines of measuring 10 year risk. The authors also make no comment on the antihypertensive drugs the patient was taking (such as angiotensin converting enzyme inhibitors and angiotensin II receptor blockers), which are often the main cause of deterioration in renal function. Stopping these will often stop the rise in creatinine concentrations and sometimes result in slow improvement in creatinine over the next couple of months.

David Ansell director, UK Renal Registry, Southmead Hospital, Bristol BS10 5 NB

david.ansell@nbt.nhs.uk

Competing interests: None declared.

1 Ratnam LA, Nelson SR, Belli AM. Investigating progressive unexplained renal impairment and hypertension. BMJ 2007:335:1094-6. (24 November.)

\section{QUALITY AND OUTCOMES FRAMEWORK}

\section{So what are we to do?}

I am astounded by Heath et al's criticism of a process they admit has not yet shown its full benefits. ${ }^{1}$ They state that, "Evidence based care was never meant to be a substitute for clinical judgment but, combined with the inducements of the quality and outcomes framework (QOF), it becomes so," which suggests that we should over-ride the evidence when it suits us.

The use of an eight year old reference about financial incentives not increasing immunisation rates in America is dubious. Does this evidence apply to 21 st century British general practice? When UK general practitioners were incentivised in the 1992 contract, immunisation rates soared. I would rather ignore the reference and believe my clinical judgment and the past 15 years' experience that payment for immunisation has given the UK one of the highest immunisation rates in the developed world.

They also say, "None of the framework measures estimate clinically important outcomes. What they assess is treatment processes that are supposed to lead to improved outcomes." What is this referring to? Glycated haemoglobin correlates with complication rates in diabetes, so measuring it and getting it below the recommended value is clinically important. Reduced blood pressure levels are a measurable and important clinical outcome in various morbidities

The government chose to incentivise general practice and to use the best available evidence at the time to measure performance. Are the authors suggesting that evidence can be ignored, experts are wrong, and GPs should forgo one of the largest investments in general practice in the past 20 years? How will this benefit patients? My clinical judgment tells me that what I am doing for my patients is improving their health so I will continue to do it, despite the current lack of evidence and Heath et al's criticism of the process.
Trefor J Roscoe general practitioner principal, Sothall Medical Centre, Sheffield S20 5JX Trefor@nhs.net

Competing interests: TJR is a GP with a high QOF score and patients who are benefiting.

1 Heath I, Hippisley-Cox J, Smeeth L. Measuring performance and missing the point? $B M$ J 2007;335:1075-6. (24 November.)

\section{Evidence of net benefit is lacking}

While on study leave in the UK, we were asked to write about the quality and outcomes framework (QOF). ${ }^{1}$ The more we read and spoke to general practitioners, the more dispirited we became. The mixture of supportive wisdom and self righteous defensive anger in the rapid responses to Heath et al's article echoes the range of views we heard. ${ }^{2}$

Clearly (to our jaundiced eyes looking down the barrel of a New Zealand QOF in the making) some saw QOF for what it is-an unfortunate and far reaching ideological experiment based on pay for performance, which has little or no rigorous evidence base.

We would argue that it is a simplistic and flawed system, which skews the value of measurability over meaningfulness (ignoring that they are often inversely related); an external, top-down imposed system of bribery that has transformed the workload and capacity of general practice; a system with unquantifiable opportunity costs in time now unavailable to deal with patients' concerns and an incremental loss of professional identity; a system based on coercion of doctors, and through them patients, and if that doesn't work, gaming through exception reporting. The result will be a perceived reduction in the need, if not (yet) ability, for individual critical thought, which will inevitably be diminished, to the disadvantage of patients.

Some GPs are doing very nicely out of QOF-so defensive and secure in their justification that they are doing a great job and that clever folk have ensured that the indicators are evidence based and that their patients must be better off.

We also met many thoughtful GPs who, while seeing some gains, are increasingly troubled and unsure of the net benefit of the system to them and their patients.

Les J Toop professor les.toop@otago.ac.nz

Dee Mangin senior lecturer, Department of General Practice University of Otago, Christchurch, New Zealand

Competing interests: LJT and DM are long term advocates for and providers of evidence informed professional education.

1 Mangin D, Toop L. The quality outcomes framework: What have you done to yourselves? Br/ Gen Pract 2007; 57:435-7.

2 Heath I, Hippisley-Cox J, Smeeth L. Measuring performance and missing the point? $B M J$ 2007;335:1075-6. (24 November.) 